\title{
Improving the efficiency of road transport companies by optimizing the costs of information and advertising activities
}

\author{
Yevgen Nagornyi ${ }^{1 *}$, Olha Shulika ${ }^{2}$, Oleksandr Severyn ${ }^{2}$, and Oleksandra Orda $^{3}$ \\ ${ }^{1}$ Kharkiv Automobile and Highway University, Ukraine \\ ${ }^{2}$ Kharkiv Automobile and Highway University, Ukraine \\ ${ }^{3}$ Kharkiv Automobile and Highway University, Ukraine
}

\begin{abstract}
In this article, we propose to improve the efficiency of transport companies by managing information and advertising activities to promote material flow. In this research, within the framework of planning the supply of consumer goods in cities, we offer the following alternative supply schemes: the direct goods delivery and delivery through distribution centres. In order to choose a rational supply scheme as a criterion of efficiency it was proposed to use the total delivery cost including the information and advertising component. The research also provides the methodology for determining the maximum effect of advertising activities by road transport companies. In addition, an example of developed advertising packages with the minimum and maximum advertising costs is given. The measures proposed in the research will allow developing a program to stimulate demand for transport services and increase the competitiveness of road transport companies in the transport market.
\end{abstract}

Key words: delivery scheme, consumer goods, road transport, advertising activity

\section{Introduction and literature review}

The transition of the national economy of Ukraine towards the "green" model of development [1] requires from the city logistics the creation of efficient freight logistics systems. They have to take into account not only the costs of participants in the planning and organization of delivery of goods but also the consequences of vehicles' use in the context of the environment $[2,3]$. An important role in this process belongs to an efficiently organized integrated logistics service using the latest innovative technologies "Industry 4.0". These technologies allow us to create a real-time planning optimization model focusing on energy efficiency of operations, the development of information and advertising management systems for companies [4]. Widespread implementation of these technologies also contributes to solving one of the key issues - the last mile problem $[5,6]$. This problem of cargo delivery to the end user is the least efficient delivery stage in cities and is up to $28 \%$ of the total delivery cost.

\footnotetext{
* Corresponding author: shulika.khnahu@gmail.com
} 
Each year, hundreds of millions of tons of different goods are delivered from suppliers to the country's distribution chains. According to researchers, today more than $60 \%$ of cargo delivery in large Ukrainian cities is carried out using the Internet for the placement delivery requests on transport portals [7]. One of the leading Ukrainian IT companies, EVO which develops online shopping space reports that in 2018, online purchases increased to a total cost of UAH 9.5 billion [8]. The Internet has changed the concept of purchasing. Logistics has such a convenient feature as an online order. As online stores have come, the customer has the opportunity to make purchases without leaving the house. At the same time, businesses that make online trading can reduce costs as salesroom lease is no more needed. Retail shops often need no warehouse. Cargo owners whose main activity was offline sales were able to expand the market and find new customers [9].

The concepts of a virtual enterprise can vary in practice from the internet site to the fullscale production and logistics system in which the web representation serves as a link between buyers, sellers and manufacturers [7]. At the same time, an important moment in advancing the services of transport companies is the development of a unique proposal that will emphasize the competitive advantages of a transport company in the transport markets. The development of an advertising proposal consists of the following steps:

- outline of potential clients: a sample of companies that may need a cargo delivery service; sending them a commercial offer;

- local media analysis. For successful promotion, it is important to choose the appropriate supply chains for advertising messages through monitoring.

However, issues of information support, speed and high cost of goods delivery remain problematic. Thus, the optimization of total costs taking into account the costs of advancing transport services will increase the efficiency of transport companies in transport markets.

\section{The mathematical model of choice a rational scheme for the delivery of consumer goods}

In this research, the following alternative delivery schemes are proposed within planning the delivery of consumer goods in cities: direct delivery of goods; delivery through distribution centres.

In order to choose a rational delivery scheme, the total delivery costs $\left(C_{l t}, \mathrm{UAH} / \mathrm{t}\right)$ under consideration of the advertising component $\left(C_{I}\right.$, UAH/time period) are taken as the criterion of effectiveness in the research. The input parameters of the delivery process model are consignment volume $(Q, \mathrm{t})$, the area of the service area $\left(\mathrm{F}, \mathrm{km}^{2}\right)$ and the intensity of the advertising effort ( $I$, days/period):

$$
C_{1 t}(Q, I, F) \rightarrow \min
$$

The given total costs are determined based on the total costs of the delivery of consumer goods $\left(C_{d e l}, \mathrm{UAH} /\right.$ period $)$ :

$$
\begin{gathered}
C_{1 t}=\frac{C_{d e l}}{Q}, \\
\mathrm{C}_{d e l}=C_{T}+C_{L U}+C_{S}+C_{I},
\end{gathered}
$$

where $C_{T}$ - transportation cost, UAH/ period; $C_{L U}$ - loading and unloading cost, UAH/ period; $C_{S}$ - storage cost, $\mathrm{UAH} /$ period. 


$$
\mathrm{C}_{I}=C_{A} \cdot Q-\delta_{m},
$$

where $C_{A}$ - unit advertising cost, $\mathrm{UAH} / \mathrm{t} ; \delta_{m}-$ unit of margin of advertising per one advertising company, UAH/ period.

System of limitations and assumptions:

$$
\left\{\begin{array}{l}
\sum_{i=1}^{N} W_{i} \geq \sum_{j=1}^{J} Q_{j} ; \\
0,05 \leq Q, \mathrm{t} \leq 25 ; \\
50 \leq L, \mathrm{~km} \leq 1500 ; \\
500 \leq I, \mathrm{UAH} / \text { month } \leq 10000 ;
\end{array}\right.
$$

where $W_{i}$ - carrying capacity of $i$-th vehicle of a road transport company, $\mathrm{t} /$ time period; $N-$ number of vehicles of carrier, ones/ period; $Q_{j}-$ the consignment volume for $i$-th request, $\mathrm{t}$ / period; $J$-number of requests to deliver, unit/ period.

To optimize the use of information and advertising activities based on the Bayesian approach [10] we proposes to establish a zone of economic expediency of advertising costs and the volume of advertising measures. It determines the amount of advertising effort (the number of advertisements, the writing of text, the adjustment of advertising by geolocation, the adjustment of advertising for a list of contacts, etc.) and their intensity.

The following dependence of advertising costs is determined:

$$
C_{A}=b \cdot I^{2}
$$

where $b$ - model parameter that characterize the intensity of cost changes, UAH/day.

The margin equation has the following form:

$$
M_{A}=-c \cdot I^{2}-d \cdot I
$$

where $c, b$ - model parameters that characterize the intensity of margin changes, UAH/day.

The area of economic feasibility of advertising costs is limited to points $A$ and $B$ shown in Fig. 1.

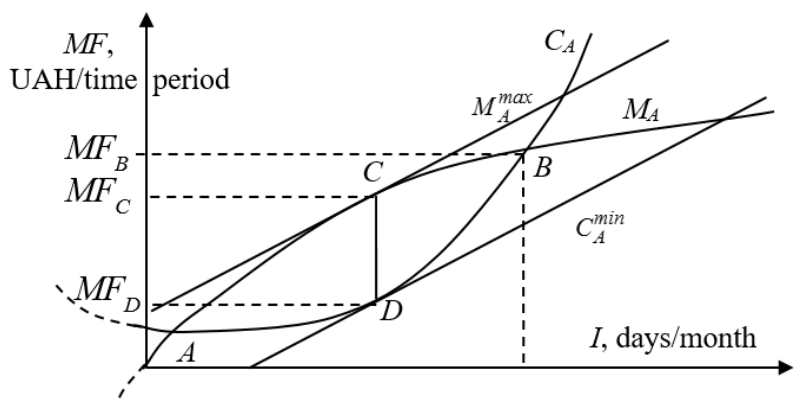

Fig. 1. Characteristic graph of dependence of margin and costs of Transport Company on the intensity of information and advertising activities.

In this case, point $B$ characterizes a situation where further increase in the volume of advertising measures becomes inappropriate. The maximum revenue from advertising measures corresponds to $C D$ segment, which represents the difference between $M F_{C}$ and $M F_{D}$ ordinates. The equation of tangent follows: 


$$
\begin{aligned}
& M_{A}^{\max }=a \cdot I+e, \\
& C_{A}^{\min }=a \cdot I-f,
\end{aligned}
$$

where $a$-parameter of straight lines, $\mathrm{UAH} / \mathrm{day} ; e, f$ - parameters of straight lines, $e>f$, $\mathrm{UAH} /$ period.

The approach to finding the ordinates of the points $C$ and $B$ consists in the fact that there are two and only two points on the cost and income curves, to which two parallel tangents can be made.

Abscise of $B$ point is calculated on condition $\frac{d M_{A}}{d I}=\frac{d M_{A}^{\max }}{d I}$, then $-2 \cdot c \cdot I_{c}-d=a$, so

$$
I_{c}=\frac{a+d}{-2 \cdot c}
$$

Abscise of $D$ point is calculated on condition $\frac{d C_{A}}{d I}=\frac{d C_{A}^{\min }}{d I}$, then

$$
2 \cdot b \cdot I_{D}=a, I_{D}=\frac{a}{2 \cdot b}
$$

Since the condition $I_{D}=I_{C}$,

$$
\begin{aligned}
& \frac{a+d}{-2 \cdot c}=\frac{a}{2 \cdot b}, \\
& d=-a \cdot\left(\frac{c}{b}+1\right) .
\end{aligned}
$$

Using the previous equations, one can calculate the ordinates of the $C$ and $D$ points:

$$
\begin{gathered}
M F_{D}=\frac{a^{2}}{2 \cdot b}-f, \\
M F_{C}=\frac{a-a \cdot\left(\frac{c}{b}+1\right)}{-2 \cdot c} \cdot a+e=\frac{a^{2}}{2 \cdot b}+e .
\end{gathered}
$$

Consequently, the length of $C D$ segment corresponding to the maximum of the effect is

$$
\Delta M F=e+f .
$$

The coordinates of the point of intersection of the income and expenditure curves that characterize the margin of economic expediency of further increasing the volume of advertising activities (the amount of information on the market situation of the collected market) can be determined provided that the functions $C_{A}(I)$ and $M_{A}(I)$ at this point are equal. That is $C_{A}(I)=M_{A}(I)$, then $(b+c) \cdot I^{2}+d \cdot I=0$, so 


$$
I_{B}=-\frac{d}{b+c}
$$

The ordinate of $B$ point follows:

$$
M F_{B}=b \cdot \frac{d^{2}}{b+c} .
$$

\section{Case study}

The area of economic expediency of advertising costs shown in Fig. 2 was determined according to the data of the Individual Entrepreneur E.V. Gayova (Kharkiv, Ukraine).

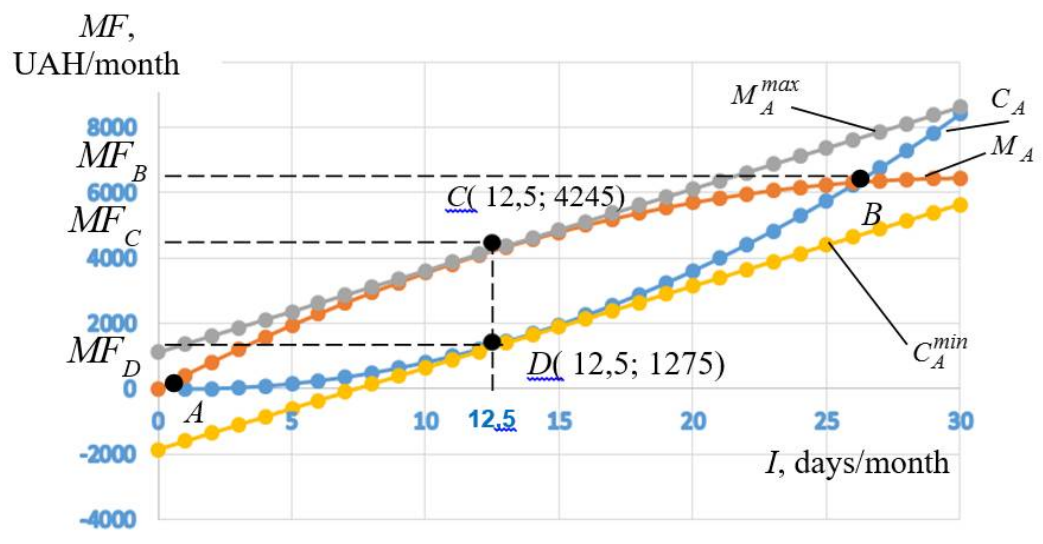

Fig. 1. Graph of dependence of margin and costs of "Gayova E.V." on the intensity of information and advertising activities.

The required amount of advertising measures that provide the optimal costs of the transport company for advertising should be 12.5 days/month, but no more than 26 days/month. At the same time, the maximum effect from the advertising impact on the consumer is equal 53,125 UAH.

The set amount of advertising costs affects the amount of advertising services. Two packages of advertising services are offered in the Table 1 for the specified enterprise proceeding from the defined zone of economic costs for advertising.

Table 1. Advertising packages with minimum and maximum advertising costs.

\begin{tabular}{|c|c|c|}
\hline Advertising service & \multicolumn{2}{|c|}{ Value } \\
\hline Package of advertising services, UAH / month & 1,275 & 4,245 \\
\hline Number of ads, units & 5 & 10 \\
\hline Text writing & + & + \\
\hline Instagram advertising & + & + \\
\hline Facebook advertising & - & + \\
\hline Create a photo and process it & + & + \\
\hline Number of taken photos, units. & 5 & 10 \\
\hline Look-a-like audience setting & - & + \\
\hline Facebook pixel settings & - & + \\
\hline
\end{tabular}

\section{Conclusion}


Thus, this approach allows, firstly, to determine the rational scheme of cargo delivery in cities, in which the total cost of delivery taking into account the costs of the transport company for advertising will be minimal. Secondly, it allows getting the maximum effect from the use of advertising activities of transport companies. It will stimulate demand for transport services and increase the competitiveness of road transport companies in the transport market.

\section{References}

1. Overview of the Ukrainian economy. American Chamber of Commerce in Ukraine [online]. Available

at: http://chamber.ua/Content/Documents/1017431819ACC_CountryProfile2018_UKR.pd f (2018)

2. F. Russo, A. Comi, A classification of city logistics measures and connected impacts. Procedia-Social and Behavioral Sciences, 2, 6355-6365 [online]. Available at: https://core.ac.uk/download/pdf/81950420.pdf (2010)

3. C. Navarro, Designing new models for energy efficiency in urban freight transport for smart cities and its application to the Spanish case. Transportation Research Procedia, 12, 314-324 (2016)

4. O. Shulika, O. Glita, The role of information and advertising activity of cargo owners in searching for freight customers in large cities. Collection of scientific works on the materials of the International scientific and practical Internet-conference "Modelling and information technologies in science, engineering and education", 246-249 [online]. Available at: http://dl.khadi.kharkov.ua/pluginfile.php/52741/mod resource/content/4/IPM_CONF SB 2018.pdf (2018)

5. L. Ranieri, S. Digiesi, B. Silvestri, M. Roccotelli, A Review of Last Mile Logistics Innovations in an Externalities Cost Reduction Vision. Switzerland: Sustainability, 10 (3), art. no. 782 (2018)

6. T. Bányai, Real-time decision making in first mile and last mile logistics: How smart scheduling affects energy efficiency of hyperconnected supply chain solutions. Energies, 11 (7), art. no. 1833 (2018)

7. A. Cherepakha, Formation of the virtual management system for delivery process of the consumer goods in large cities: aref... PhD, spec.: 05.22.01 - Transport System. KhNAHU [online]. Available at: https://dspace.khadi.kharkov.ua/dspace/bitstream/123456789/1860/1/\%D0\%A7\%D0\% B5\%D1\%80\%D0\%B5\%D0\%BF\%D0\%B0\%D1\%85\%D0\%B0 \%D0\%B0\%D1\%80\% D0\%B5\%D1\%84.pdf (2016)

8. Evo.company [online]. Available at: https://evo.company/category/media-aboutus/evo/(2019)

9. A. Pakholkova, Analysis of new information technologies used in logistics. Current issues of economics and management: Proceedings of the IV International. scientific conference, 170-174 (2016)

10. O. Smekhov, Marketing model of transport market. - Moskow: Publishing groupe «Transport» (1998) 